\title{
ПРОГРАММЫ ДЛЯ ЭВМ КАК РЕЗУЛЬТАТ ИНТЕЛЛЕКТУАЛЬНОЙ ДЕЯТЕЛЬНОСТИ, ИХ СПЕЦИФИКА И ПРОБЛЕМАТИКА
}

\section{COMPUTER PROGRAMS AS A RESULT OF INTELLECTUAL ACTIVITY, THEIR SPECIFICS AND PROBLEMS}

E. Lineitsev

Summary. Due to the rapid development of scientific and technological progress and the development of computer technologies, the author believes that such a result of intellectual activity as a computer program deserves special attention. Due to the dual nature of computer programs: the presence of features inherent in both objects of copyright and patent law - there are discussions among supporters of the idea of their legal protection by copyright or patent law. In this article, the author will consider the features of computer programs, the criteria of protectability as an object of copyright and patent law.

Keywords: Intellectual property, computer software, legal protection, copyright, patenting law.

\author{
Линейцев Евгений Анатольевич \\ Аспирант, ФГБОУ ВО «Байкальский государственный \\ университет», г. Иркутск \\ e.lineytsev@mail.ru
}

Аннотачия. Из-за стремительного развития научно-технического прогресса и развития компьютерных технологий особое внимание по мнению автора заслуживает такой результат интеллектуальной деятельности как программа для ЭВМ. В Связи с двойственной природой программ для ЭВМ: наличие черт, присущих как объектам авторского права, так и патентного права — возникают дискуссии среди сторонников идеи их правовой охраны нормами авторского права или нормами патентного права. В данной статье автор рассмотрит особенности программ для ЭВМ, критерии охраноспособности как объекта авторского и патентного права.

Ключевые слова: интеллектуальная собственность, программа для ЭВМ, авторское право, патентное право.

Но в отличии от литературных произведений, в отношении программ для ЭВМ законодателем предусмотрена возможность добровольной государственной регистрации. При наличии регистрации все операции по распоряжению исключительного права, а именно: лицензионные договоры о предоставлении права использования, договоры об отчуждении, залоге исключительного права - также подлежат государственной регистрации в федеральном органе исполнительной власти по интеллектуальной собственности [1, с. 60].

Следующая особенность программы для ЭВМ состоит в том, что для использования программы для ЭВМ необходимо наличие лицензионного соглашения, которое обычно заключается в упрощенном порядке. При этом условия договора излагаются на экземпляре программы либо на ее упаковке, либо в электронном виде. Данная договорная конструкция является договором присоединения и получила название «коробочная лицензия».

Как в теории, так и на практике возникают проблемы в целесообразности охраны программы для ЭВМ нормами авторского права и их патентоспособность.

Каждое произведение, в том числе программа для ЭВМ, для защиты авторского права должно соответ- 
ствовать ряду критериев. На наш взгляд, стоит сказать о двух основных критериях охраноспособности произведения как объекта авторского права.

В соответствии с пунктом 3 статьи 1259 ГК РФ авторские права распространяются как на обнародованные, так и необнародованные результаты интеллектуальной деятельности, выраженные в какой - либо объективной форме.

Исторически в законодательстве существовала норма, которая говорила, что форма выражения произведения должна быть такой, чтобы позволяла его воспроизводить, под ним понимается повторное придание объективной формы, т.е. создание экземпляра произведения. В юридической доктрине существовало две позиции относительно соотношения объективной формы и воспроизводимости произведения. Относительно первой, воспроизводимость и объективная форма является одним критерием, при этом воспроизводимость выступает в роли формы, в которой оно (произведение) выражено. Относительно второй позиции, воспроизводимость является самостоятельным критерием. На данный момент российское законодательство не закрепляет указанный критерий в качестве обязательного.

Современное законодательство предъявляет лишь одно требование к форме выражения произведения это возможность его восприятия другими лицами. Согласно положениям Бернской конвенции 1886 года странами-участницами может быть закреплено, что защита прав не предоставляется в отношении результатов интеллектуальной деятельности, не имеющих материальной формы.

Критерий наличия объективной формы является важным, так как он свидетельствует о возможности человека почувствовать произведение. Должна быть какая-либо степень фиксации - это может быть и публичное исполнение, и закрепление на материальном носителе, и существование в цифровой сфере. И, если в отношении соответствия программ для ЭВМ данному критерию у авторов не возникает проблем и различных интерпретаций, то в отношении следующего критерия не существует однозначной точки зрения.

Вторым критерием является творческая составляющая результата интеллектуальной деятельности. В законе нет ее четкого определения, но в статье 1228 ГК РФ сказано, что не может являться автором гражданин, не внесший своего творческого вклада в результат интеллектуальной деятельности.

В отечественной литературе выделяют два подхода к определению творческой составляющей: субъектив- ный и объективный. Субъективный подход основан на выражении личности автора в своем произведении. Объективный подход основывается не на личностных (эмоциональных) вложениях автора; а на новизне, оригинальности, неповторимости, творческом характере самого произведения.

Современное законодательство отдает приоритет субъективному подходу, основываясь на том, что отсутствие новизны, уникальности не может свидетельствовать о нетворческом труде автора,

По мнению Чурилова А.Ю., творческий характер программы для ЭВМ проявляется в создании особых алгоритмов или последовательностей операций, а также сама архитектура программы в случае, если является выдающимся результатом творческого труда [2, с. 95].

Мы считаем, что творческий характер заключается в наличии уникального «авторского» стиля, индивидуальности применения алгоритмов и операций, а не в создании принципиального нового программного кода. Первоочередным, на наш взгляд, является творческое выражение идеи, а не технические особенности ее выражения.

Если же говорить об охране программы для ЭВМ нормами патентного права, то есть несколько существенных особенностей, значительно усложняющих переход на эту форму охраны.

Во-первых, критерии охраноспособности в патентном праве: новизна, изобретательский уровень и промышленная применимость [3, с. 50].

Изобретение для получения охраны должно иметь изобретательский уровень, то есть для специалиста оно явным образом не следует из уровня техники, является неочевидным.

Следующим условием патентоспособности является его промышленная применимость, данный следует толковать максимально широко, подразумевая любую сферу применения.

И если последние не вызывают трудностей, то относительно новизны программ для ЭВМ возникают вопросы, так как в основном для патентного права первоочередным является именно содержание изобретения, а не его форма. При этом все основные алгоритмы и технические решения разработчикам программ давно известны.

Во-вторых, выдача патентов на программы для ЭВМ приведет к монополизации рынка программного обе- 
спечения крупными компаниями, отсутствию конкуренции, стагнации программного обеспечения, увеличения числа плагиата и распространение «пиратской продукции».

С другой стороны, патентная охрана с большей степенью защитит имущественные права авторов, поскольку на первый план выдвинутся идеи и методы, которые составляют суть программы - результата интеллектуальной деятельности автора.

Таким образом, можно сделать вывод, что программа для ЭВМ является специфическим объектом права, совмещающим в себе черты и патентного, и авторского права, что вызывает значительные сложности в их охране и правовом регулировании.

\section{ЛИТЕРАТУРА}

1. Мерзляков А.П. Компьютерные программы как объекты права интеллектуальной собственности // ИС. Авторское право и смежные права. 2020. N7. C. 59-64.

2. Чурилов А.Ю. Проблемы охраны программ для ЭВМ // Вестник Саратовской государственной юридической академии. 2020. N. 1. С. 94-101.

3. Чурилов А.Ю. Патентная охрана в индустрии видеоигр через призму патентования программ для ЭВМ // ИС. Промышленная собственность. 2020. N12. C. 42-50.

(с) Линейцев Евгений Анатольевич ( e.lineytsev@mail.ru ).

Журнал «Современная наука: актуальные проблемы теории и практики»

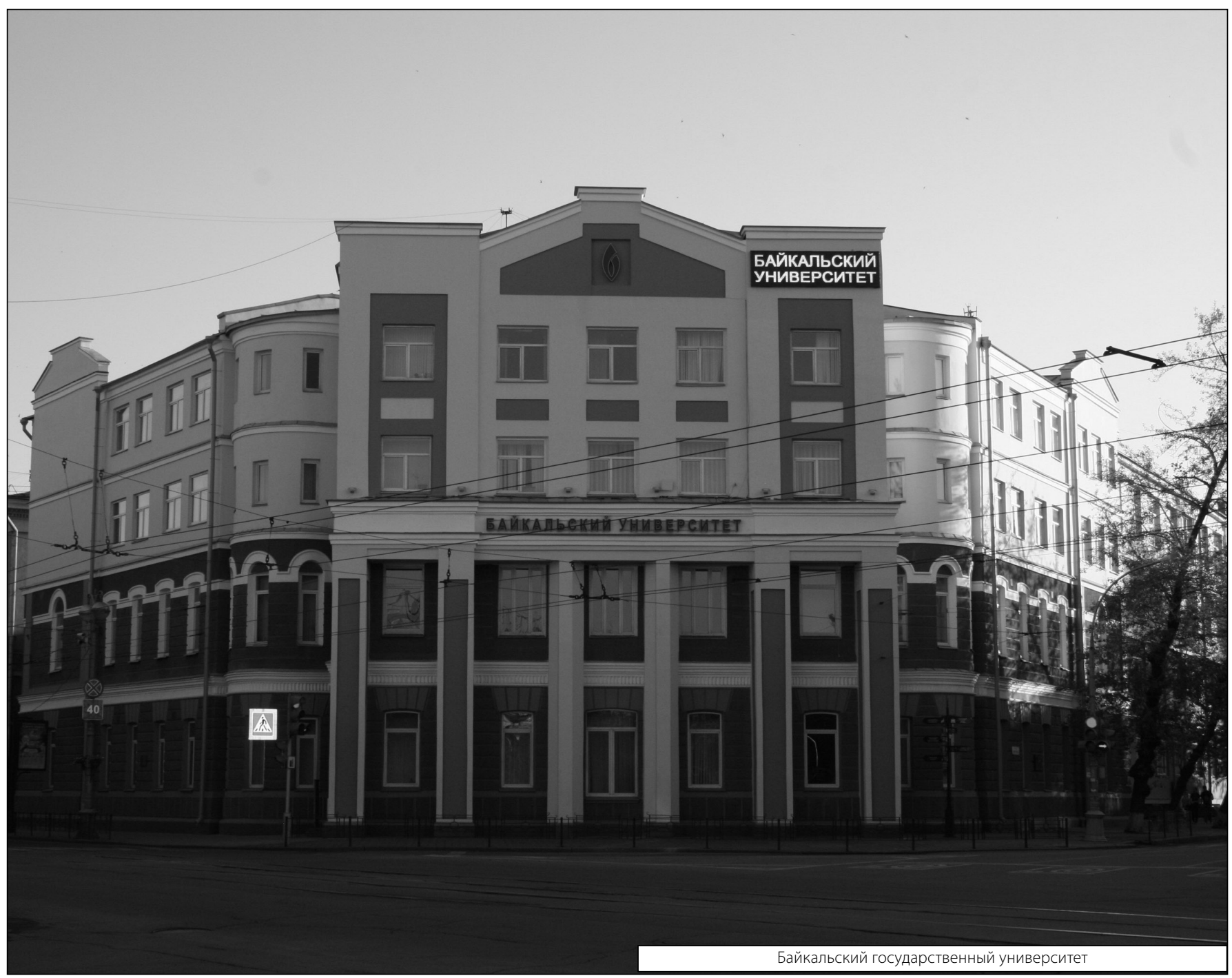

